\title{
A study on pregnancy outcome in patients with first trimester vaginal bleeding
}

\author{
Kavyashree H. S. ${ }^{1}$, Rajeshwari K. ${ }^{2 *}$
}

\begin{abstract}
${ }^{1}$ Department of Obstetrics and Gynecology, Mysore Medical College and Hospital, Mysore, Karnataka, India ${ }^{2}$ Department of Obstetrics and Gynecology, Chamarajanagara Institute of Medical Sciences, Yadapura, Karnataka, India
\end{abstract}

Received: 03 February 2019

Accepted: 08 February 2019

\author{
*Correspondence: \\ Dr. Rajeshwari K., \\ E-mail: statisticsclinic2018@gmail.com
}

Copyright: $($ ) the author(s), publisher and licensee Medip Academy. This is an open-access article distributed under the terms of the Creative Commons Attribution Non-Commercial License, which permits unrestricted non-commercial use, distribution, and reproduction in any medium, provided the original work is properly cited.

\begin{abstract}
Background: Vaginal bleeding is a common obstetric problem and a cause of anxiety and worry both to patients and the Obstetrician. The common cause of bleeding in 1st trimester include various types of abortion, ectopic pregnancy and molar pregnancy. This study was conducted to assess the maternal and perinatal outcome in pregnant women who present with first trimester vaginal bleeding.

Methods: A Prospective study (Longitudinal study) among pregnant women presenting with First trimester bleeding was conducted for a period from November 2017 to Jan 2019 at Mysore Medical College and Hospital 200 subjects were included into the study by Multiphasic sampling method using a structured questionnaire to collect the data.

Results: The study observed that among 200 subjects who were included in the study $123(61.5 \%)$ were non-viable pregnancy and $67(38.5 \%)$ were viable pregnancy. Among 67 viable pregnancy only 30 (47\%) had no obstetrical complications, $11(17.1 \%)$ aborted and others had problems of PROM, Preterm labour, Placenta previa, IUGR and IUD.

Conclusions: It can be concluded that first trimester bleeding is a predicting factor for obstetric and perinatal complications during pregnancy. Hence it is necessary to increase the knowledge of pregnant women in this regard for closer care. It is also important factor for clinician to be attentive towards first trimester bleeding in providing clinical interventions for the continuation of pregnancy and also reducing the fetal complications in these high-risk pregnancies.
\end{abstract}

Keywords: First trimester bleeding, Pregnancy outcome, Vaginal bleeding

\section{INTRODUCTION}

The first trimester of pregnancy is a dynamic period that spans ovulation, fertilization, implantation, and organogenesis. Vaginal Bleed in early pregnancy represents a definite threat to developing embryo and constitutes a source of Anxiety to both the patient and the clinician. Vaginal Bleed during first trimester has been estimated to occur in 16 to $25 \%$ of all pregnant women. ${ }^{1,2}$ A spectrum of causes for first trimester Bleed has been identified ranging from Threatened Abortion, Complete
Abortion. Incomplete Abortion, Missed Abortion, Gestational Trophoblastic disease, Ectopic Gestation. It is also one of the common causes of emergency admissions to the obstetrical department and common reason for ultrasound in 1 st trimester. $^{3}$ Hence complications occurring during this period pose a diagnostic and management challenge to the obstetrician.

Meta-analysis indicate that vaginal bleeding is associated with two-fold increased risk of other complications during pregnancy. ${ }^{4}$ In first trimester pregnancies 
Complicated by bleed less than $50 \%$ progress normally beyond 20 weeks of Gestation, 10-15\% will be ectopic pregnancy, $0.2 \%$ will be a hydatidiform mole and $30 \%$ miscarry Approximately 5\% of Women elect to terminate the pregnancy. About $15 \%$ of Pregnancies are complicated by Threatened miscarriage. Threatened Abortion has been shown to be associated with an increased risk of poor obstetric outcomes such as preterm labour, Low birth weight and premature rupture of Membranes. Moreover, when pregnant - women have bleeding, it may cause stress and anxiety for the Mother to be about the outcome of pregnancy. This can be a difficult time for women because of uncertainty of outcome, lack of preventive measures and emotional significance of early pregnancy loss. Although few studies have evaluated outcomes other than viability at term. Most agree that adverse pregnancy outcome is associated with first trimester vaginal Bleed. The outcome of ongoing pregnancies after first firmest bleeding is of relevance to women and obstetricians for planning antenatal care and clinical interventions in pregnancy. Definitive diagnosis of First trimester vaginal bleeding is necessary to save the life of the pregnant patient especially in the pathological conditions like ectopic, if not promptly diagnosed can lead to torrential bleed that can end the life of poor mothers.

The important diagnostic action in patients with first trimester vaginal bleeding after confirmation of positive pregnancy test is Transvaginal sonogram to identify normal or pathological condition to provide early intervention..$^{5,6}$

Hence this study was conducted to identify the risks associated with first trimester bleed which may facilitate decision making regarding mode, place and timing of delivery during management, which may improve maternal and neonatal outcome. The objective of the present study was to assess the maternal and perinatal outcome in pregnant women who present with first trimester vaginal bleeding.

\section{METHODS}

A prospective study (longitudinal study) among pregnant women presenting with First trimester bleeding was conducted for a period from November 2017 to Jan 2019 at Mysore Medical College and Hospital.

\section{Inclusion criteria}

- All the women with vaginal bleeding in $1^{\text {st }}$ trimester of pregnancy whose pregnancy was confirmed by urine pregnancy test.

\section{Exclusion criteria}

- All non-obstetrics cause of vaginal bleeding

- All patients $>12$ completed weeks
- Pregnant women with chronic medical complications like diabetes, hypertension was excluded from the study.

\section{Sample size}

Sample size was estimated based on the $34 \%$ abortion rate from the study by Zhila Amirkhani et al. ${ }^{3}$ At $10 \%$ error and 99\% Confidence interval sample size was 149 and expecting 10\% nonresponse rate sample size was 149 $+15=164$ cases. Were as during the study period around 200 cases were encountered who fulfilled the inclusion criteria and they were included in the study and followed up. Formula used to estimate sample size:

$\mathrm{N}=1.962 \mathrm{p}(1-\mathrm{q}) / \mathrm{d}^{2}$

\section{Sampling method}

Multiphasic sampling method was used to collect the data.

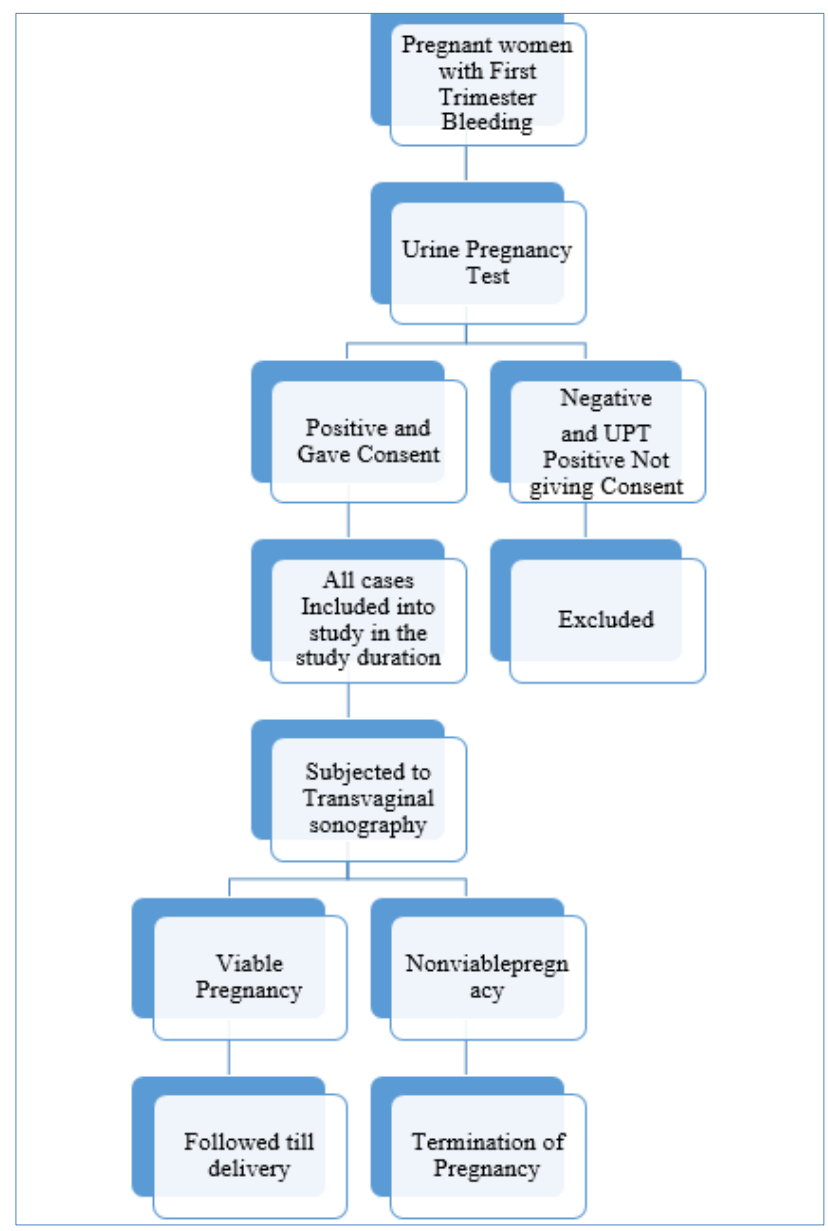

Figure 1: Multiphase sampling for selection of cases.

\section{Method of collection of data}

Pregnant women with First trimester bleeding were evaluated by clinical history and examination and later 
subjected to Urine pregnancy testing. Eligible candidates were selected after the exclusion criteria and informed consent was taken from them for participating in the study. All the women fulfilling the inclusion criteria and gave informed consent during June 2010 to Jan 2012 were included in to the study by multiphasic sampling method. Later these subjects were subjected to Transvaginal sonogram and were divided into 2 groups:

- Non-viable pregnancy

- Viable pregnancy.

Those with nonviable pregnancy was terminated, patient with ectopic underwent definitive treatment and patients with molar gestation underwent suction and evacuation. Those patients with viable pregnancy were followed with regular antenatal check up every 15 days till 32 weeks and weekly thereafter.

Later the outcome of pregnancy was assessed in the form of obstetrical complications like placenta previa, PROM, preterm labour, IUD and perinatal outcome like prematurity, low birth weight, low APGAR, NICU admission, perinatal mortality.

\section{RESULTS}

Majority of subjects were in the age group 21 to 25 years (40\%), $60 \%$ were multigravida and $40 \%$ were primigravida, $55 \%$ were from rural areas (Table 1).

Table 1: Social profile of the study subjects.

\begin{tabular}{|c|c|c|c|}
\hline \multicolumn{2}{|c|}{ Parameters } & \multirow{2}{*}{$\begin{array}{l}\text { No. of patients } \\
(n=200) \\
25\end{array}$} & \multirow{2}{*}{$\begin{array}{l}\% \\
12.5\end{array}$} \\
\hline \multirow{4}{*}{$\begin{array}{l}\text { Age } \\
\text { (years) }\end{array}$} & $18-20$ & & \\
\hline & $21-25$ & 80 & 40 \\
\hline & $26-30$ & 60 & 30 \\
\hline & $31-35$ & 35 & 17.5 \\
\hline \multirow[t]{2}{*}{ Parity } & Primigravida & 80 & 40 \\
\hline & Multigravida & 120 & 60 \\
\hline \multirow[t]{2}{*}{ Place } & Urban & 90 & 45 \\
\hline & Rural & 110 & 55 \\
\hline
\end{tabular}

In the study among 200 subjects 64 (32\%) had viable pregnancy in USG and threatened abortion and they were followed up. 136 (68\%) had Non-viable pregnancy.

Table 2: Outcome of pregnancy among the pregnant women with first trimester bleeding.

\begin{tabular}{l|l|l|l|}
\begin{tabular}{l|l|l|} 
USG \\
finding
\end{tabular} & Pregnancy outcome & $\begin{array}{l}\text { No. of cases } \\
(\mathbf{n = 2 0 0})\end{array}$ & $\%$ \\
\hline $\begin{array}{l}\text { Viable } \\
\text { pregnancy }\end{array}$ & Threatened abortion & 64 & 32 \\
\hline $\begin{array}{l}\text { Non- } \\
\text { viable } \\
\text { pregnancy }\end{array}$ & Abortion & 123 & 61.5 \\
\cline { 2 - 4 } & Ectopic gestation & 8 & 4 \\
\hline & Molar gestation & 5 & 2.5 \\
\hline & Total & 200 & 100 \\
\hline
\end{tabular}

Among Non-viable pregnancy 123 aborted, 5 had molar gestation and 8 had ectopic gestation which were terminated (Table 2). In the study it was observed that among 64 subjects with viable pregnancy, $67 \%$ had term delivery, $15.6 \%$ had preterm delivery and $17.2 \%$ had abortion during the follow up. Among 53 subjects who delivered $81 \%$ delivered by normal vaginal delivery and $19 \%$ by lower caesarian section (Table 3 ).

\section{Table 3: Pregnancy outcome among pregnant with} viable pregnancy.

\begin{tabular}{|l|l|l|l|}
\hline \multirow{2}{*}{ Pregnancy } & Nutcome & No of cases & $\%$ \\
\hline \multirow{2}{*}{$\begin{array}{l}\text { Outcome } \\
\text { of delivery }\end{array}$} & Term delivery & 43 & 67 \\
\cline { 2 - 4 } & Preterm delivery & 10 & 15.6 \\
\cline { 2 - 4 } & Abortion & 11 & 17.2 \\
\hline \multirow{2}{*}{$\begin{array}{l}\text { Type of } \\
\text { delivery }\end{array}$} & Normal delivery & 43 & 81 \\
\cline { 2 - 4 } & Caesarian section & 10 & 19 \\
\hline
\end{tabular}

When bleeding pattern was observed among non-viable and viable pregnancy. Moderate and Severe bleeding was more commonly associated with Non-Viable pregnancy (32\% and 24\% respectively). Spotting was commonly associated with Threatened abortion (62.5\%). Hence there was statistically significant association between Bleeding and Type of Abortion.

Among subjects with threatened abortion few of them had 2-3 episodes of spotting in the subsequent trimester also. But none of them had adverse perinatal outcome. All had live born child.

Patient with molar gestation and ectopic presented with moderate amount of flow. Those with heavy bleeding $15.7 \%(\mathrm{n}=10)$ in first trimester continued to bleed in $2 \mathrm{nd}$ trimester also and all 10 patients ended up in miscarriage. Those with moderate bleeding during the 1st trimester continued to bleed on and off subsequently and had significant complications namely LBW, Placenta Previa, PROM, Preterm labor, IUGR, IUD, perinatal mortality (Table 4).

Table 4: Pattern of bleeding among subjects with nonviable pregnancy and threatened abortion.

\begin{tabular}{|l|l|l|l|l|}
\hline $\begin{array}{l}\text { Bleeding } \\
\text { pattern }\end{array}$ & $\begin{array}{l}\text { Non-viable } \\
\text { pregnancy } \\
(\mathrm{n}=136)\end{array}$ & $\%$ & $\begin{array}{l}\text { Viable } \\
\text { pregnancy } \\
(\mathbf{n = 6 4})\end{array}$ & $\%$ \\
\hline Spotting & 60 & 44 & 40 & 62.5 \\
\hline Moderate & 44 & 32 & 14 & 21.8 \\
\hline Severe & 32 & 24 & 10 & 15.7 \\
\hline Total & 136 & & 64 & \\
\hline $\mathrm{X} 2=5.884, \mathrm{df}=2, \mathrm{p}<0.05$ & & & \\
\hline
\end{tabular}

$\mathrm{X} 2=5.884, \mathrm{df}=2, \mathrm{p}<0.05$

Pregnant women with complete abortion and threatened abortion $(n=85)$ were managed conservatively. Pregnant with complete abortion were discharged with haematinics and those with threatened miscarriage $(n=64)$ were managed conservatively with restricted activity, regular prenatal care. Patient with incomplete abortion $(n=28)$, 
inevitable abortion $(n=7)$, molar gestation $(n=5)$ and few patients with missed miscarriage $(n=18)$ underwent suction and evacuation. Rest of the patient $(n=49)$ with missed abortion had dilatation and curettage done. Patient with ruptured ectopic $(n=5)$ underwent laparotomy and simultaneous resuscitation, and those with unruptured ectopic underwent laparoscopic salpingectomy (Table 5).

Table 5: Ultrasound findings in pregnant women with first trimester vaginal bleeding.

\begin{tabular}{|l|l|l|}
\hline USG features & $\begin{array}{l}\text { No. of patients } \\
(\mathbf{n = 2 0 0})\end{array}$ & $\%$ \\
\hline Gestational sac & 132 & 66 \\
\hline Fetal pole & 96 & 48 \\
\hline Fetal cardiac activity present & 64 & 32 \\
\hline Sub chorionic hemorrhage & 36 & 18 \\
\hline Low placenta & 11 & 5.5 \\
\hline Ectopic pregnancy & 8 & 4 \\
\hline Molar pregnancy & 5 & 2.5 \\
\hline
\end{tabular}

Pregnant women with complete abortion and threatened abortion $(\mathrm{n}=85)$ were managed conservatively. Pregnant with complete abortion were discharged with haematinics and those with threatened miscarriage $(n=64)$ were managed conservatively with restricted activity, regular prenatal care (Table 6).

Table 6: Management of pregnant women with first trimester vaginal bleeding.

\begin{tabular}{|l|l|l|}
\hline Management & No. of cases & $\%$ \\
\hline Conservative & 85 & 42.5 \\
\hline Suction and evacuation & 58 & 29 \\
\hline Dilatation and curettage & 49 & 24.5 \\
\hline Laparotomy & 5 & 2.5 \\
\hline Laparoscopy & 3 & 1.5 \\
\hline Total & 200 & 100 \\
\hline
\end{tabular}

Patient with incomplete abortion $(n=28)$, inevitable abortion $(n=7)$, molar gestation $(n=5)$ and few patients with missed miscarriage $(n=18)$ underwent suction and evacuation. Rest of the patient $(n=49)$ with missed abortion had dilatation and curettage done. Patient with ruptured ectopic $(n=5)$ underwent laparotomy and simultaneous resuscitation, and those with unruptured ectopic underwent laparoscopic salpingectomy.

\section{DISCUSSION}

In the present study it was observed that $70 \%$ of them were in the age group 21 to 30 years and $60 \%$ were multigravidas and perhaps the reason is that majority of delivery also occur in this age group. Previous history of abortion was observed among $46(38.3 \%)$ of multigravida subjects, of which $36.9 \%$ had viable pregnancy and $63.1 \%$ had non-viable pregnancy. In the study done by Zhila Amir Khani et al also observed similar pattern of observations, that among pregnant women with first trimester bleeding $53.3 \%$ were in the age group 25 to 35 years. $^{3} 15 \%$ had history of previous abortion and $33.3 \%$ had previous history of bleeding during pregnancy. Spotting was observed in $3.3 \%$, moderate bleeding was observed in $73.3 \%$ and severe bleeding was observed in $23.3 \%$. Reem Hasan et al in there study also observed similar pattern that majority of subjects were in the age group 28 to 34 years $(45.9 \%), 34.8 \%$ were primipara and $17.7 \%$ were multipara. Spotting was seen in $75.6 \%$ of subjects, light bleeding in $18.4 \%$ and $6.1 \%$ had heavy bleeding. ${ }^{7}$

Basama FM et al in their study observed that parity, previous miscarriage, the amount and number of episodes of vaginal bleeding seem to have no influence in the rate of miscarriage. Similarly, in the present study there was no significant association between previous bad obstetric history and bleeding. ${ }^{8}$ In the present study 64 (32\%) had viable pregnancy in USG and were labelled as threatened abortion and they were followed up for the outcome. 136 $(68 \%)$ had Non-viable pregnancy. In the study by Dogra et al it was reported that three major reasons for first trimester bleeding are abortion, EP and trophoblastic diseases in the pregnancy. ${ }^{9}$

In the present study, the evaluation of uterus and pregnancy sac by ultrasound was considered as the first necessary action for diagnosis of the cause of bleeding. All the pregnant patients with h/o vaginal bleeding in the first trimester underwent Transvaginal sonogram. Gestational sac was observed in $66 \%$ of subjects, Fetal pole in $48 \%$ of subjects, Fetal cardiac activity was present in $32 \%$, Sub chorionic hemorrhage was observed in $18 \%$, Low placenta was observed in $5.5 \%$, Ectopic pregnancy was seen in $4 \%$ and Molar Pregnancy was seen in $2.5 \%$.

The studies of Deutchman et al. and Thorstensen et al. reported that in pregnancies with first trimester bleeding the most important diagnostic actions include transvaginal ultrasound and evaluating the rising of serum level of $\beta \mathrm{HCG}^{5,6}$ Aziz S, Cho RC, Bater DB concluded that in pregnant with Vaginal bleeding, embryos of $5 \mathrm{~mm}$ and smaller without a heartbeat all resulted in pregnancy failure. ${ }^{10}$ After sonography of pregnancies with first trimester bleed and a small intrauterine gestational sac without a demonstrable embryo Falco P, Zagonari S, Gabrielli S, found that in cases with threatened abortion demonstration by transvaginal sonography of an intrauterine gestational sec $<16 \mathrm{~mm}$ without an embryo may be compatible with a viable pregnancy. ${ }^{11}$ They suggested that this finding was associated with a poor outcome, with miscarriage occurring in two thirds of patients.

\section{CONCLUSION}

Hence considering the results of present study, it can be concluded that first trimester bleeding is a predicting factor for obstetric and perinatal complications during pregnancy. Hence it is necessary to increase the 
knowledge of pregnant women in this regard for closer care. Especially for those who had previous bad obstetric history and also initiation of early antenatal care for Primigravida for early recognition of high-risk cases. It is also important factor for clinician to be attentive towards first trimester bleeding in providing clinical interventions for the continuation of pregnancy and also reducing the fetal complications in these high-risk pregnancies. Knowledge of this increased risk may also facilitate decision making regarding management, mode, place and time of delivery which will inevitably improve pregnancy outcome.

\section{Recommendations}

The study recommends for counseling of the women with first trimester vaginal bleeding, especially with previous bad obstetric history and threatened miscarriage. Proper antenatal care and follow up has to be given to women who present with first trimester bleeding. To clinical it recommends having high suspicion towards first trimester bleeding and to evaluate them with USG for diagnosis and better management of subjects.

Funding: No funding sources Conflict of interest: None declared

Ethical approval: The study was approved by the Institutional Ethics Committee

\section{REFERENCES}

1. Goldman JA, Ashkenazi J, Ben-David M, Feldberg D, Dicker D, Voliovitz I. First trimester bleeding in clinical IVF pregnancies. Hum Reproduct. 1988;3(6):807-9.

2. Stabile I, Campbell S, Grudzinskas JG. Ultrasound and circulating placental protein measurements in complications of early pregnancy. $\mathrm{Br} \mathrm{J}$ Obstet Gynaecol.1989;96(10):1182-91.

3. Zhila Amir Khani, Meisam Akhaghdoust Media Abedian, Gelareh Rabie, Salehi, maternal and perinatal outcome in pregnant women with first trimester vaginal bleeding. J Fam Reproduct Health. 2013;7(2):57-61.

4. Sotiriadis A, Makrydimas G, Papatheodorou S, Loannides JP. Expectant management of first trimester miscarriage. Meta-analysis OBG 2003; 105(5 pt 1):1104-13.

5. Deutchman M, Tubay AT, Turok D. First trimester bleeding. Am Fam Physician. 2009;79(11):985-94.

6. Thorstensen KA. Midwifery management of first trimester bleeding and early pregnancy loss. J Midwifery Women's Health. 2000;45(6):481-97.

7. Reem Hasan, Donna D. Baird, Amy H. Herring, Andrew F. Olshan, Michele L. Jonsson Funk, and Katherine E. Hartmann. Patterns and predictors of vaginal bleeding in the first trimester of pregnancy. Ann Epidemiol. 2010;20(7):524-31.

8. Basama FM, Crosfill F.The outcome of pregnancies in 182 women with threatened miscarriage. Arch Gynecol Obstet. 2004;270(2):86-90.

9. Dogra V, Paspulati RM, Bhatt S. First trimester bleeding evaluation. Ultrasound Q. 2005;21(2):6985.

10. Aziz S, Cho RC, Baker DB, Chhor C, Filly RA. Five-millimeter and smaller embryos without embryonic cardiac activity: outcomes in women with vaginal bleeding.J Ultrasound Med. 2008; 27(11):1559-61.

11. Falco P, Zagonari S, Gabrielli S, Bevini M, Pilu G, Bovicelli L. Sonography of pregnancies with firsttrimester bleeding and a small intrauterine gestational sac without a demonstrable embryo.Ultrasound Obstet Gynecol. 2003;21(1):625 .

Cite this article as: Kavyashree HS, Rajeshwari K. A study on pregnancy outcome in patients with first trimester vaginal bleeding. Int J Reprod Contracept Obstet Gynecol 2019;8:820-4. 